See Article page 1561.

\section{Commentary: Durable left ventricular assist device infections: A call to arms}

\author{
Walker M. Blanding, MD, and Arman Kilic, MD
}

Innovation in the realm of durable left ventricular assist devices (LVAD) has changed the landscape of advanced heart failure and provided hope for patients with otherwise dismal prognosis with regard to survival and quality of life. Nevertheless, adverse events such as renal failure, right heart failure, device malfunction, and infection account for a significant morbidity and mortality burden for LVAD populations. ${ }^{1,2}$ Likosky and colleagues ${ }^{3}$ present their work on durable LVAD health care-associated infection and its influence on Medicare costs as well as other adverse events.

The authors make creative work of the Society of Thoracic Surgeons Intermacs database as well as 90-day Medicare claims to evaluate the cost of health careassociated infection in this patient subset. Of those undergoing LVAD implantation, $27.8 \%$ developed a health care-associated infection. The payment groups were divided into terciles with the upper tercile accounting for $9 \%$ higher payments compared with the lower tercile with an absolute difference of $\$ 13,600$. The majority of this difference was accounted for during the postimplant period and the trend held steady for both device-related and nondevice-related infections. The upper tercile of health care-associated infections was also associated with longer lengths of intensive care unit stay after implant, more renal dysfunction requiring dialysis, higher pulmonary artery pressures, higher incidence of need for right ventricular

From the Division of Cardiothoracic Surgery, Medical University of South Carolina, Charleston, SC.

Disclosures: Dr Kilic is on the medical advisory board for Medtronic, Inc, and a speaker/consultant for Abiomed. Dr Blanding reported no conflicts of interest.

The Journal policy requires editors and reviewers to disclose conflicts of interest and to decline handling or reviewing manuscripts for which they may have a conflict of interest. The editors and reviewers of this article have no conflicts of interest.

Received for publication June 9, 2021; revisions received June 9, 2021; accepted for publication June 10, 2021; available ahead of print June 17, 2021.

Address for reprints: Arman Kilic, MD, Division of Cardiothoracic Surgery, Medical University of South Carolina, 30 Courtenay Dr, MSC 295, Suite BM 279, Charleston, SC 29425 (E-mail: kilica@musc.edu).

J Thorac Cardiovasc Surg 2022;164:1570-1 $0022-5223 / \$ 36.00$

Copyright $\Subset 2021$ Published by Elsevier Inc. on behalf of The American Association for Thoracic Surgery

https://doi.org/10.1016/j.jtcvs.2021.06.018

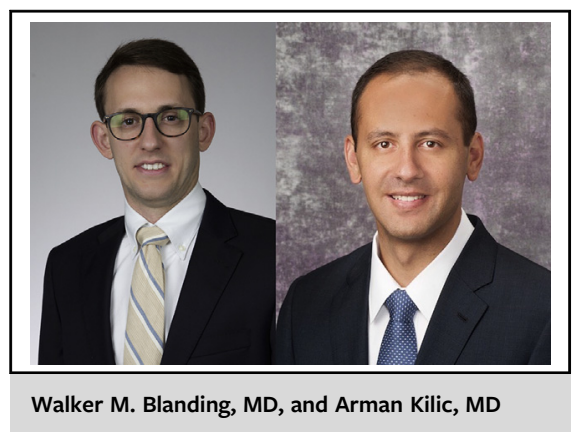

CENTRAL MESSAGE

Postimplant ventricular assist

device infection rates vary

significantly across institutions,

carry significant cost, and are

associated with other predictors

of postoperative morbidity and

mortality.

mechanical assist, more reoperation for bleeding, and increased respiratory failure rates.

Although it seems natural to recognize that those patients who develop an unexpected infection while hospitalized will utilize more resources and ultimately cost the system more, this work shows the exponential effect this can have in complex LVAD patients who require a high level of care at baseline. Perhaps more importantly, the work shows the association with major other morbidities and mortality in the LVAD population. Although it is unclear from these data which variables may act as confounders, it is clear that patients who get infections are significantly sicker and place a higher burden on the system.

Clinicians know too well the challenge of rescuing LVAD patients from multisystem organ failure and sepsis. Although even the lowest tercile of hospitals still carry a significant infection burden contributing to this, the study does point out a high and perhaps unacceptable variability of $37 \%$ among Intermacs hospitals in terms of overall and risk-adjusted infection rates, which is significantly higher than other benchmarked cardiac operations. ${ }^{4,5}$ These data should perhaps be a call for the heart failure community for standardization for infection control practices in hopes of providing higher quality of care and better use of resources. Moreover, adopting best practices from centers with lower infection rates and lower failure to rescue from major infection rates may improve outcomes on a broader 
scale. This should be a multidisciplinary effort with input from various stakeholders, including experts in infectious disease. Further research aimed at providing more granularity regarding infection types and severity as well as specific practices to limit the burden of infection would be prudent.

\section{References}

1. Tattevin P, Flécher E, Auffret V, Leclercq C, Boulé S, Vincentelli A, et al. Risk factors and prognostic impact of left ventricular assist device-associated infections. Am Heart J. 2019;214:69-76.
2. Patel CB, Blue L, Cagliostro B, Bailey SH, Entwistle JW, John R, et al. Left ven tricular assist systems and infection-related outcomes: a comprehensive analysis of the MOMENTUM 3 trial. J Heart Lung Transplant. 2020;39:774-81.

3. Likosky DS, Yang G, Zhang M, Malani PN, Fetters MD, Strobel RJ, et al. Interhospital variability in health care-associated infections and payments after durable ventricular assist device implant among Medicare beneficiaries. J Thorac Cardiovasc Surg. 2022;164:1561-8.

4. Likosky DS, Wallace AS, Prager RL, Jacobs JP, Zhang M, Harrington SD, et al Sources of variation in hospital-level infection rates after coronary artery bypass grafting: an analysis of The Society of Thoracic Surgeons Adult Heart Surgery database. Ann Thorac Surg. 2015;100:1570-5.

5. Kirklin JK, Naftel DC, Kormos RL, Stevenson LW, Pagani FD, Miller MA, et al. Fifth INTERMACS annual report: risk factor analysis from more than 6000 mechanical circulatory support patients. J Heart Lung Transplant. 2013;32:141-56. 